\title{
The Ethics of Food and Childhood Obesity - A Public Health
}

\section{Issue}

\author{
EVANGEL SARWAR, Ph.D., MPH
}

evangel.sarwar@gmail.com

\begin{abstract}
Adequate food consumption is essential to stay alive. However, overconsumption and consumption of nutritionally deficient food can increase risks of obesity that negatively impacts health; ultimately leading to more expensive medical treatments, reduced quality of life, and early death - making it a public health issue. The World Health Organization (WHO) notes there is an increase in the prevalence of infant, childhood and adolescent obesity, and this is alarming because obesity can affect a child's immediate health, educational attainment, and quality of life. Overweight children are likely to be obese as an adult and consequently be at risk for various chronic illnesses. The prevalence of severe obesity in the United States has alarmingly increased among children, and research suggests that approximately $90 \%$ of children with severe obesity will become obese adults depending on the age at which these children became obese. This only shows that obesity is a precursor for a far more significant public health crisis that is about to explode with time. Moreover, obesity is also associated with the development of psychosocial implications such as diminished self-esteem and self-worth as a result of associated social and peer stigma. According to experts, the focus on childhood obesity should be on prevention rather than on the treatment of obesity. Even though obesity has been identified as the overconsumption of calorically dense and high-fat foods and inadequate physical activity, there is a socioeconomic dimension to the obesity crisis. This raises ethical questions regarding the role of government in implementing policies to eliminate obesity. To address obesity, it is better to understand it at the community level. Better policies that address the socioeconomic issues and environmental factors that fuel the obesity epidemic are needed - with that in mind; this paper aims to target these issues at the community and policy level.
\end{abstract}

\section{INTRODUCTION}

Adequate food is critical for people to stay alive. However, overconsumption and consumption of nutritionally poor food can increase risks of obesity that negatively impacts health; ultimately leading to more expensive medical treatments, reduced quality of life, and early death. ${ }^{(1)}$ The rise of obesity has become a public health challenge. ${ }^{(2)}$ Some ethical concerns related to food are related to the rise of obesity in adults and children. The World Health Organization (WHO) has associated obesity with globalization processes that include mass industrialization, and rapid urbanization. However, these macro-level forces have different effects even within the same country or city.

*Address correspondence to: Evangel Sarwar. Ph.D., E-mail: evangel.sarwar@gmail.com

+To cite this article: Evangel Sarwar "The Ethics of Food and Childhood Obesity - A Public Health Issue," The Journal of Healthcare Ethics \& Administration 5, no. 1 (Fall/Winter 2019): 7-21, https://doi.org/10.22461/jhea.1.71621

This work is brought to you for free and open access by the Institute of Clinical Bioethics (ICB) at Saint Joseph's University, Philadelphia, PA, U.S.A. It has been accepted for inclusion in The Journal of Healthcare Ethics \& Administration by the editorial board and an authorized administrator of the JHEA. For more information, please contact support@jheaonline.org

\footnotetext{
${ }^{1}$ Alexandra Brewis, Obesity: Cultural and biocultural perspectives. (New Brunswick, New Jersey and London: Rutgers University Press, 2011), 1

${ }^{2}$ Ronald L. Sandler, Food ethics: The basics. (Abingdon: Routledge, 2015), 145
} 
Even though obesity has been identified as the overconsumption of calorically dense and high-fat foods and inadequate physical activity, there is a socioeconomic dimension to the obesity crisis. ${ }^{(3)}$ This raises ethical questions regarding the role of government in implementing policies to eliminate obesity. To address obesity, it is better to understand it at the community level. ${ }^{(4)}$ There is a need for better policies that address socioeconomic issues and environmental factors that play a role in the obesity epidemic. Looking at the socioeconomic and environmental factors that have contributed to the obesity epidemic is the focus of this paper, intending to make recommendations targeting these at the community and policy level.

\section{THE PROBLEM OF THE OBESITY EPIDEMIC}

The prevalence of obesity has increased dramatically over the past few decades, with the United States of America having the highest prevalence of obesity of any country in the developed world at 39\% according to the World Health Organization (WHO). ${ }^{\text {(5) }}$ Despite the slow start, the concern of obesity has dramatically grown in the last decade or so, focused especially on its health impacts. Obesity is associated with the elevated risk of hypertension, type 2 diabetes, coronary heart disease, stroke, gall bladder disease, cancers and other noncommunicable diseases (NCD), ultimately leading to more complicated and expensive medical treatment, reduced life and early death - making it a public health issue. ${ }^{(6)}$ Billions of dollars in medical expenses due to weightrelated issues are lost each year, and billions more are lost through decreased work capacity, disability, missed work days and early death. The Sustainable Development Goals (SDG), set by the United Nations in 2015, identify prevention and control of noncommunicable diseases (NCD) as core priorities. Obesity, in particular, has been identified among the NCD risks to play a negative role in the health benefits that have already contributed to the increased life expectancy. ${ }^{(7)}$ It has been reported by the WHO that there is an increase in the prevalence of infant, childhood and adolescent obesity, and this is alarming because obesity can affect a child's immediate health, educational attainment, and quality of life; and overweight children are likely to be obese as adult and consequently be at risk for various chronic illnesses. This section looks at the health burden associated with obesity and looks at why childhood obesity is especially an important issue.

\section{A. The health burden of obesity}

The epidemic of obesity poses a grave threat to the health of the people of the United States. ${ }^{(8)}$ According to Alexandra Brewis, obesity in adults is the level of fat at which the health and well-being of people are negatively impacted. ${ }^{(9)}$ Globally, the body mass index (BMI) is most commonly used to estimate obesity. ${ }^{(10)}$ Since 1980 , the doubling rate of obesity has contributed to nearly 1.5 billion (35\%) adults being overweight, and 500 million of whom (200 million men and 300 million women) are clinically obese, highlighting itself as a public health challenge that needs to be monitored by public agencies. The World Health Organization has recently assessed that over a third of the people are now overweight or obese. If this continues, it is estimated that over a third of the people will become obese, and this has already been the case in many industrialized countries, including the United States. ${ }^{(11)}$

According to scholars like Per-Anders Tengland, a systematic review of the economic burden of obesity worldwide demonstrated that $0 \bullet 7-2 \bullet 8 \%$ of a country's total healthcare costs were obesity-related, and accounted for $30 \%$ higher medical costs for obese people than those with normal weight; and obesity was projected to attribute to 16 - $18 \%$ of the total US healthcare

\footnotetext{
${ }^{3}$ Ronald L. Sandler, Food ethics: The basics, 154

${ }^{4}$ Alexandra Brewis, Obesity: Cultural and biocultural perspectives, 2-3

${ }^{5}$ World Health Organization WHO: Fact Sheet (2016)

${ }^{6}$ Ryan T. Hurt et al. "The Obesity Epidemic: Challenges, Health Initiatives, and Implications for Gastroenterologists" Gastroenterol Hepatol, 6 no 12(2010):781

${ }^{7}$ Report of the commission on ending childhood obesity. World Health Organization (2016): 8

${ }^{8}$ William H. Dietz. "The Response of the US Centers for Disease Control and Prevention to the Obesity Epidemic." Annual Review of Public Health 36 (2015): 576

${ }^{9}$ Alexandra Brewis, Obesity: Cultural and biocultural perspectives, 11

${ }^{10}$ Alexandra Brewis, Obesity: Cultural and biocultural perspectives, 12

${ }^{11}$ Alexandra Brewis, Obesity: Cultural and biocultural perspectives, 2
} 


\section{THE JOURNAL OF HEALTHCARE ETHICS \& ADMINISTRATION}

Vol. 5 | No. 1 (Fall/Winter 2019)

expenditure by 2030. ${ }^{(12)}$ More than 150 million Americans are overweight or obese, and across the globe, an estimated 1.5 billion are affected. One-quarter to one-third of all cancers can be attributed to obesity. The diseases associated with obesity cost our medical system an estimated $\$ 147$ billion per year. There are emotional pains also that makes the condition difficult to bear. ${ }^{(13)}$

In addition to the medical costs that represent monetary value of healthcare resources, obesity contributes to societyincurred costs, such as obesity-related disability, increased rate of mortality, early retirement and reduced social productivity that are significantly higher than the monetary costs of medical costs. ${ }^{(14)}$ Increased risk of NCD due to excess body weight contributes to many non-fatal but costly disabilities such as osteoarthritis, benign prostate hypertrophy, infertility, asthma, and sleep apnea. Moreover, Y. Claire Wang and colleagues point out in their study that maternal obesity has been linked to an increased risk of congenital anomalies, and because the prevalence of obesity at a younger age is high in many populations, this raises the concern for a projected higher proportion of the population with chronic disabilities. ${ }^{(15)}$

Although the causes of obesity are considered to be multifactorial, a clear role has been established for the influence of food availability, portion size, industry marketing practices, and low levels of physical activity. ${ }^{(16)}$ According to the director of the US Centers for Disease Control and Prevention (CDC) - obesity has been declared as an epidemic in the United States - and environmental determinants of obesity must be acknowledged. ${ }^{(17)}$ The role of dietary risk factors in NCD is now well recognized. Dietary risk factors have been calculated to account for approximately $14 \%$ of disability-adjusted life-years and approximately $26 \%$ of deaths in the United States. Indeed, the transition from a traditional diet toward a diet composed of more industrialized, refined, and energy-dense foods has led to the well-known epidemic of obesity and diet-related chronic diseases (DRCD). ${ }^{(18)}$

The World Health Organization (WHO) classifies overweight among the major health threats of this century. Worldwide obesity has tripled since 1975 (WHO), with more than 1.9 billion adults, 18 years and older, were noted to be overweight in 2016 . Of these over 650 million were obese. Moreover, over 340 million children and adolescents aged 5-19 were overweight or obese in 2016, as observed by the WHO. ${ }^{(19)}$ A recent study by Robert Hammond and colleagues (2019), also noted $18.5 \%$ of US children and adolescents (2-9 years) had obesity as of 2016, with significantly higher prevalence in boys than girls. ${ }^{(20)}$ Obesity can have severe physical, social and psychological consequences in addition to being a major risk factor for potential life-threatening NCDs. Furthermore, obesity can cause several negative effects on the quality of life, such as debilitating conditions with adverse effects on quality of life, such as respiratory difficulties, chronic musculoskeletal problems, and infertility. ${ }^{(21)}$ The massive increase in obesity has been attributed to environmental changes; diets high in sugars and fats; sedentary lifestyles; increased access to low-priced processed foods; and urbanization. ${ }^{(22)}$

\section{B. Childhood obesity}

The prevalence of severe obesity in the United States has alarmingly increased among children. ${ }^{(23)}$ Research by Jantina de Vries suggests approximately $90 \%$ of children with severe obesity will become obese adults. Jantina de Vries also adds that obesity in children leads to earlier development of NCD such as atherosclerosis, and type 2 diabetes. The fast-paced growth rate of overweight and obesity in children leads to increased concern for health issues related to excess body fat in children and morbidity related to obesity in adulthood. Evidence suggests that there are 6-7 times higher chances that obese children will become obese adults,

\footnotetext{
${ }^{12}$ Per-Anders Tengland, "Behavior Change or Empowerment: On the Ethics of Health-Promotion Strategies". Public Health Ethics, 5(2012): 2

${ }^{13}$ Deborah Cohen, A Big Fat Crisis: The Hidden Forces Behind the Obesity Epidemic - and How We Can End It. (New York NY: Nations Books, 2014), 13

${ }^{14}$ Y. Claire Wang et al. "Severe Obesity In Adults Cost State Medicaid Programs Nearly \$8 Billion In 2013" Health Affairs, 34, no.11 (2015):1923

${ }^{15}$ Y. Claire Wang et al. "Severe Obesity In Adults Cost State Medicaid Programs Nearly \$8 Billion In 2013", 1927

${ }^{16}$ Y Claire Wang, et al. "Obesity 2: Health and economic burden of the projected obesity trends in the USA and the UK." Lancet, 378 (2011): 817

${ }^{17}$ Y Claire Wang, et al. "Obesity 2: Health and economic burden of the projected obesity trends in the USA and the UK", 815

${ }^{18}$ Ross Upshur. “What Does Public Health Ethics Tell (Or Not Tell) Us About Intervening in Non-Communicable Diseases?” Bioethical Inquiry (2013) 10:20

${ }^{19}$ William H. Dietz. "The Response of the US Centers for Disease Control and Prevention to the Obesity Epidemic", 576

${ }^{20}$ Anthony Fardet and Yves Boirie. "Associations between food and beverage groups and major diet-related chronic diseases: an exhaustive review of pooled/ meta-analyses and systematic reviews" Nutrition Reviews, 72 no 12 ():741

21 "Fact sheets: overweight and obesity: key facts." World Health Organization.

${ }^{22}$ Robert Hammond et al. "Predicting Childhood Obesity Using Electronic Health Records and Publicly Available Data." Plos One 14, no. 4 (2019):2

${ }^{23}$ Marieke ten Have Page 303. Marieke ten Have et al. "An overview of ethical frameworks in public health: can they be supportive in the evaluation of programs to prevent overweight?" BMC Public Health, 638 no 10 (2010): 303
} 


\section{THE JOURNAL OF HEALTHCARE ETHICS \& ADMINISTRATION}

Vol. 5 | No. 1 (Fall/Winter 2019)

depending on the age at which these children became obese. This only shows that obesity is a precursor for a far larger public health crisis that is about to explode with time. ${ }^{(24)}$

Currently, the BMI for age ranging from $85^{\text {th }}$ to greater than the $95^{\text {th }}$ percentile is notably higher than it was in the 1980 s. ${ }^{(25)}$ Data shows that 6.5 percent of children between the ages of six to 11, and 5 percent of children between the ages of 12 to 19 were considered as overweight before 1980. However, this data has significantly increased to 18.8 percent in children aging six to 11 and 17.4 percent in children aging 12 to 19 , with an additional 31 percent of children under 18 at high risk of being overweight. Alarmingly, if this trend continues, obesity expenditures in the US have been projected to account for more than $\$ 860$ billion by 2030, of which 16 percent will account for healthcare expenditures due to obesity-related issues per Shawn Lawrence and colleagues. ${ }^{(26)}$

Unfortunately, child and adolescent overweight and obesity are influenced at multiple levels; and although genetic characteristics may increase susceptibility - biological influence within the context of environmental influences are more prominent determinants of child and adolescent overweight and obesity. It has been observed that children with two obese parents may be genetically susceptible to being overweight - suggesting that a slight increase in food consumption in a child with overweight parents may contribute to a larger weight gain for the child as compared with a child with non-overweight parents. Scholars have also noted behaviors with food consumption and physical activities linked to weight outcomes in children. Obesity is consider ed as a result of behavioral choices. However, individuals are also living in 'obesogenic' environments where high-caloric foods are overabundant, time is restricted, and exercise has become a matter of choice rather than obligation. ${ }^{\text {(27) }}$

Children with obesity and overweight issues are also psychologically affected. They suffer from depression, anxiety and eating disorders. Their self-esteem, perception of ability and self-confidence are also negatively influenced, ultimately affecting their physical activity levels as well as food consumption habits and choices. Familial influences also play a role and range from nonsupportive home environments and poor shared family health habits. Fifty percent of the children who are neglected are more likely to become obese as compared to children not neglected according to research. Neglected children tend to overeat as a means of comfort, and become obese in the process. Parental influence plays a role in role modeling and positively influencing belief in the child's ability. ${ }^{(28)}$

According to Caroline M. Apovian, the priority of national public health efforts has shifted from "treatment of adulthood obesity to the prevention of childhood and adolescent overweight and obesity." As noted by the U.S. Department of Health and Human Services (HHS) Healthy People 2010 initiative, the national emphasis was placed on the child and adolescent weight status, which identified overweight and obesity as "one of 10 leading indicators of public health." Moreover, overweight and obesity is associated with chronic physical illnesses linked to chronic health complications, which are related to psychosocial implications such as diminished self-esteem and self-worth as a result of associated social and peer stigma. These have demonstrated negative effects on the targeted youths' self-esteem and psychosocial functioning and levels of depression. According to experts, the focus on childhood obesity should be on prevention rather than on the treatment of obesity. ${ }^{\text {(29) }}$

Moreover, the media has been sending the wrong message to people that obesity is a matter of personal responsibility. Anti-fat messages and perceptions that body weight is within personal control have been communicated far too often by the media. This has served in highlighting the social message that obesity is a "personal responsibility" and has enabled stigmatization, and justification of the stigma as an acceptable societal response. ${ }^{(30)}$ Which has resulted in a $66 \%$ rise in weight discrimination over the past decade, and is now comparable to the racial discrimination rate in the United States of America. Although stigma has been

\footnotetext{
${ }^{24}$ Alexandra Brewis, Obesity: Cultural and biocultural perspectives, 5

${ }^{25}$ Caroline M. Apovian, "The Obesity Epidemic - Understanding the Disease and the Treatment". The new England Journal of Medicine, 374 (2016): 177

${ }^{26}$ Vries, Jantina de. "The obesity epidemic: medical and ethical considerations". Sci Eng Ethics 13(2007):57

${ }^{27}$ Shawn Lawrence, Rehekah Hazlett, and Peggy Hightower. "Understanding and Acting on the Growing Childhood and Adolescent Weight Crisis: A

Role for Social Work." National Association of Social Workers, (2010): 147

${ }^{28}$ Shawn Lawrence, Rehekah Hazlett, and Peggy Hightower. "Understanding and Acting on the Growing Childhood and Adolescent Weight Crisis: A Role for Social Work, 149

${ }^{29}$ Shawn Lawrence, Rehekah Hazlett, and Peggy Hightower. "Understanding and Acting on the Growing Childhood and Adolescent Weight Crisis: A Role for Social Work, 148

${ }^{30}$ Caroline M. Apovian, "The Obesity Epidemic - Understanding the Disease and the Treatment", 178
} 
known to impose sufferings on vulnerable groups, and impaired efforts to progression - the stigma of obesity has not been addressed as a concern in the combat for obesity and is rarely discussed in public health. ${ }^{\text {(31) }}$

Although obesity rates have dramatically risen, weight stigma is still not given the same level of serious recognition as it deserves. Public health needs to address these issues and recognize the harm that weight stigma has on the quality of life of overweight people. To address the obesity epidemic, there is a need to optimize the current and future public health interventions to prevent obesity - starting with recognizing the impact of weight stigma. There are significant environmental contributors to obesity that are beyond individual control - such as changes in the food environment today, that promote and reinforce obesity. Some examples include the increased access to cheap, unhealthy fast foods; significant marketing and advertising of unhealthy, energy-dense foods by the food industry that contribute to excessive food consumption especially in children, who are heavily targeted. In this fight against obesity, we need to stop targeting the individual as the villain, as well as the solution for obesity. ${ }^{(32)}$

\section{SOCIAL AND ETHICAL ISSUES}

Childhood obesity in the United States presents major health challenges, but it has not been easy to identify effective ways to reverse childhood obesity. ${ }^{(33)}$ Although unhealthy diet and lack of physical activity has been commonly associated with obesity, research by the WHO (2016) suggests that the condition is aggravated by "Obesogenic Environments" that foster high energy intake and sedentary life behavior. Environments are tied to socioeconomic conditions such as income, education, access to transportation, access to healthy food, physical activity opportunities, ethnicity, and culture. People are also stigmatized by others because of weight; as a result, they struggle with weight and often stigmatize themselves- feel inferior, ashamed, unhappy and even depressed. People want them to believe it is their lack of control. The stereotypical view that overweight people lack self-discipline and is less competent is plain wrong. ${ }^{(34)}$ There are ethical issues with this view, and we must recognize that an individual's ability to resist overeating is limited when excess food is constantly available. ${ }^{(35)}$ All of these issues raise the most basic ethical and policy questions as to what is the ethical assessment of public health strategies to prevent childhood obesity in regards to the role of government, and society's obligations to protect and nurture children, i.e., who provides food to minors? How can we protect children from falling prey to the advertisement of unhealthy food choices? Personal responsibility should be a second priority after adequate environments have been provided. ${ }^{(36)}$ The next section looks at the factors that are attributed to the rise in the obesity epidemic.

\section{A. Urbanization, nutrition transition, socioeconomics, and obesogenic environment}

The rapid increase in obesity is tied to massive recent changes in our food systems, often called nutrition transition; which according to Alexandra Brewis is the term applied to the substantive shifts in the diet that have accompanied the global process of "urbanization, modernization, and industrialization." As the author points out, the transition is initiated when diets rich in whole grains, vegetables, and relatively lean proteins - are replaced over time by diets based on more processed foods which have high contents of sugar, saturated fat, and sodium. (37) Most studies attribute the American obesity epidemic to two principal environmental reasons - decreasing cost and the increasing availability of food (especially in the form of fast or junk food), and the

\footnotetext{
${ }^{31}$ Rebecca M. Puhl, and Chelsea A. Heuer “Obesity Stigma: Important Considerations for Public Health.” American Journal of Public Health, 100, no 6 (2010): 1021

32 Rebecca M. Puhl, and Chelsea A. Heuer “Obesity Stigma: Important Considerations for Public Health”, 1019

${ }^{33}$ Rebecca M. Puhl, and Chelsea A. Heuer “Obesity Stigma: Important Considerations for Public Health", 1020

${ }^{34}$ Kersh R, Stroup DF, Taylor WC. "Childhood obesity: a framework for policy approaches and ethical considerations." Prev Chronic Dis: 8 no 5(2011): 1

${ }^{35}$ Deborah Cohen, A Big Fat Crisis: The Hidden Forces Behind the Obesity Epidemic - and How We Can End It, 14

${ }^{36}$ Deborah Cohen, A Big Fat Crisis: The Hidden Forces Behind the Obesity Epidemic - and How We Can End It, 15

${ }^{37}$ Kersh R, Stroup DF, Taylor WC. "Childhood obesity: a framework for policy approaches and ethical considerations", 2
} 


\section{THE JOURNAL OF HEALTHCARE ETHICS \& ADMINISTRATION}

Vol. 5 | No. 1 (Fall/Winter 2019)

decline of physical activity. ${ }^{(38) .}$ Technological advances in food processing lowered the cost of unhealthy food and made it possible to maintain longer shelf life; making overeating of these unhealthy foods affordable. (39)

Additionally, these dietary changes are also associated with lifestyle transitions such as changes in occupation and leisure time activities which tend to promote a relatively sedentary lifestyle. However, obesity rates are not evenly distributed - varies within regions, even within localized areas. Location seems to have a profound influence on body size and the risk of obesity. (40) Differences in obesity risks have been observed in differences between neighborhoods. Obesity is related to variations in the built environment between different cities or different parts of the city. For example, some parts of the city are considered as "obesogenic" environments, when they do not provide a structure that allows/accommodates a physical activity, thus causing weight gain. While other parts of the city may be "leptogenic," meaning they are structured in ways that strongly encourage or even demand physical activity and causes a reduction in weight. ${ }^{(41)}$ The consensus is that childhood obesity risk declines with access to local opportunities for physical activity. There is also evidence that popular suburban neighborhoods with low-density housing, culde-sacs and heavy reliance on cars tend to be associated with higher BMI.

Food insufficiency remains an issue in obesity, especially with huge gaps between rich and poor. ${ }^{(42)}$ It has been estimated by the United States Department of Agriculture's (USDA) report that 11.8 percent American households were food insecure at least sometime during 2017, which meant that they did not have "access to enough food for an active, healthy life for all household members." ${ }^{\prime(3)}$ According to studies, higher BMls were tracked in children in food-insufficient households. ${ }^{(44)}$ Addressing obesity involves improving people's diet and promoting regular physical activity. There are structural factors that make these difficult everything from where we live to the economics of food matter. ${ }^{(45)}$ To reduce obesity people need to have access to healthier foods and the opportunity for physical activity. There are two aspects to this problem - availability and choice. ${ }^{(46)}$ Food availability is an issue - people who do not have access to healthy food are left with no choice but to purchase dense calorie food high in fat and sugar, rather than healthier, nutritionally rich foods, particularly when the former are less expensive and more readily available. The demands of city life combined with relative access to prepared, unhealthy food make it harder to make time for shopping, preparing and cooking healthy food at home. ${ }^{(47)}$

Studies also show those of lower socioeconomic status report greater insecurity in terms of the probability of losing one's job, having no health insurance, or being the victim of a burglary. Unemployment among parents appears to be stressful for children. Adolescent boys with unemployed parents were less likely to be confident about the future or to be independent and hopeful than boys from families that didn't face this problem. Further, adolescents who attempt suicide are more likely than other adolescents to have an unemployed father. ${ }^{(48)}$ High job demands with low control over work have also been found to be stressful. (49) The relationship between stress and weight gain may have to do with the total amount of life stress the individual suffers. Modern humans live in multiple domains: households, workplaces, neighborhoods, social networks, a political world, and a macroeconomic world. Stress in any particular domain might be expected to impact individuals differently. Nevertheless, studies found that employees suffering from chronic work stress have approximately 50 percent higher odds of obesity compared with those without work stress. ${ }^{(50)}$ Findings from studies suggest that a country's degree of income inequality is positively and statistically

\footnotetext{
${ }^{38}$ Alexandra Brewis, Obesity: Cultural and biocultural perspectives, 48

39 Jon D. Wisman and Kevin W. Capehart. "Creative Destruction, Economic Insecurity, Stress, and Epidemic Obesity". American Journal of Economics and Sociology, 69 no. 3 (2010): 938

40 Deborah Cohen, A Big Fat Crisis: The Hidden Forces Behind the Obesity Epidemic - and How We Can End It, 72

${ }^{41}$ Alexandra Brewis, Obesity: Cultural and biocultural perspectives, 59

${ }^{42}$ Alexandra Brewis, Obesity: Cultural and biocultural perspectives, 60

${ }^{43}$ Alexandra Brewis, Obesity: Cultural and biocultural perspectives, 53

${ }^{44}$ Alisha Coleman-Jensen et al. "Household Food Security in the United States in 2017." USDA ERS, (2018):44

${ }^{45}$ Alexandra Brewis, Obesity: Cultural and biocultural perspectives, 54

${ }^{46}$ Ronald L. Sandler, Food ethics: The basics, 155

${ }^{47}$ Ronald L. Sandler, Food ethics: The basics, 156

${ }^{48}$ Alexandra Brewis, Obesity: Cultural and biocultural perspectives, 51

49 Jon D. Wisman and Kevin W. Capehart. "Creative Destruction, Economic Insecurity, Stress, and Epidemic Obesity", 956

50 Jon D. Wisman and Kevin W. Capehart. "Creative Destruction, Economic Insecurity, Stress, and Epidemic Obesity", 957
} 


\section{THE JOURNAL OF HEALTHCARE ETHICS \& ADMINISTRATION}

Vol. 5 | No. 1 (Fall/Winter 2019)

significantly associated with the prevalence of obesity among both men and women. ${ }^{(51)}$ Thereby, these findings suggest that income gaps contribute to obesity, with the risk shifting down the SES ladder. ${ }^{(52)}$

Food deserts are also contributors to obesogenic environments - these are areas where access to fresh, healthy food at a reasonable price is limited. Some rural areas are food deserts, in that one has to travel some distance to access reasonably priced, healthy food. ${ }^{(53)}$ In such areas, people have to have their own reliable transportation to get to food stores. In low-income areas, one may find few widely spaced full-service supermarkets. Residents without transportation or extra time are more likely to shop at convenience stores; which are typically packed with food with long shelf lives that tend to be highly processed and mass produced, high in corn syrup and sugar, and laden with cheap oil - these are high in calories and low in nutrients by both weight and price. Higher densities of fast food restaurant add to the obesogenicity, putting unhealthy but very cheap meal choices within a short walking distance, leading to fast food consumption, and promoting the risk of nutritional morbidities at the neighborhood level. (54)

People can be time poor as well as money poor; this phenomenon is critical in thinking about associations between income, poverty and obesity risk. Low- and middle-income households in the industrialized West and urban families in developing economies, have to make difficult trade-offs between how they use their money and their time. Where people have sedentary or fixed-location jobs with long, inflexible hours, time poverty can be a real problem for both eating and exercising. Families in poverty tend to face the most difficult trade-offs because their choices are often so comparatively limited. ${ }^{(55)}$ When both parents are working and money is still short there is less time in the house for sourcing and preparing meals that may require greater shopping effort and preparation time. Shopping for and preparing food from scratch can take effort; fast food or prepared foods often high in fat and low in nutritional value, are increasingly the most time thrifty and often the cheapest available calories. Families who eat together tend to eat fewer fatty foods and more fruits and vegetables, but the growing norm in working families is to spend less at the grocery store, and more at fast-food restaurants, and pre-prepared foods. Exercise also requires a time investment for people with sedentary jobs. ${ }^{(56)}$

The emergence of fast food establishments, greater portion size, the availability of soda and other so-called "junk food," insufficient physical activity are amongst the many factors that directly aid in the increase of the obesity epidemic. Location is also a factor as previously mentioned. Even though fast food restaurants are a relatively new phenomenon that began less than 55 years ago, with the very first McDonalds opening in San Bernardino in California in 1957, the number of fast food restaurants has exponentially grown, and so has an obesity epidemic. Numbers quite often can demonstrate the enormity of the problem. In 1958, there were an estimated 600 fast food establishments in the US, as of 2010 that changed to an estimated 222,000 fast food restaurants in the United States alone. So, in less than 55 years the number of fast food restaurants has grown exponentially and so coincidentally has the obesity epidemic. There is a tremendous physical, social, and psychological burden that severe obesity causes in a growing number of American youth. ${ }^{(57)}$ The stigma around weight and obesity remains at large in the United States, leading to great social, economic, and health disparities. ${ }^{(58)}$

\section{B. Social consequences of obesity - prejudice, stigma, and bias}

Obesity carries a negative connotation in numerous societies, where many cultures judge beauty by weight - such as the saying, "You can never be too rich or too thin." Many people view the overweight as greedy, lazy and lethargic; and overweight people are ignored - as a result, obesity can have serious economic, psychological and social consequences. Society's weight bias leaves people who are obese vulnerable to depression, anxiety, and lowered self-image and, in some instances, suicidal ideation. The social

\footnotetext{
51 Jon D. Wisman and Kevin W. Capehart. "Creative Destruction, Economic Insecurity, Stress, and Epidemic Obesity”, 959

52 Alexandra Brewis, Obesity: Cultural and biocultural perspectives, 64

53 Alexandra Brewis, Obesity: Cultural and biocultural perspectives, 61

${ }^{54}$ Alexandra Brewis, Obesity: Cultural and biocultural perspectives, 62

${ }^{55}$ Alexandra Brewis, Obesity: Cultural and biocultural perspectives, 69

${ }^{56}$ Deborah Cohen, A Big Fat Crisis: The Hidden Forces Behind the Obesity Epidemic - and How We Can End It, 73

57 Jeffrey L. Fortuna, "The Obesity Epidemic and Food Addiction: Clinical Similarities to Drug Dependence". Journal of Psychoactive Drugs, 44 no 1(2012): 57

${ }^{58}$ Caroline M. Apovian, "The Obesity Epidemic - Understanding the Disease and the Treatment", 179
} 


\section{THE JOURNAL OF HEALTHCARE ETHICS \& ADMINISTRATION}

Vol. 5 | No. 1 (Fall/Winter 2019)

gradient of obesity is due to a social gradient of insecurity and stress. ${ }^{(59)}$ Today, where weight and economic well-being are inversely related, indicates that obesity and its related health risks disproportionately affect those of lower socioeconomic status. The obese, in particular, are stigmatized - they overeat food, eat too many unhealthy foods, and exert themselves too little. Studies show that political leaders tend to regard obesity as a disorder of individual behavior, rather than highly conditioned by the socioeconomic environment. The social gradient can be accounted for by inequities in access to healthy foods, gym memberships, expensive weight-loss programs, and gastric bypass surgery, and health information. ${ }^{(60)}$

A weakness of the character or will, shame, and moral failure, and guilt has all been associated with obesity. It is believed that body image preferences play a part in the social consequences of obesity. Slim ideals may penetrate more readily or forcefully in some groups and places than in others. ${ }^{(61)}$ Some even think that obesity is a self-inflicting condition, and obese people are responsible for their own situation. Obesity is a low prestige condition, and interventions can be viewed as tools for moral disdain. As Bjørn Hofmann adds in his research, that "despite exertions to expel moral disdain from conceptions of disease, the issue of selfcontrol and self-infliction still appears to be haunting, e.g., in demand for mandatory preoperative dietary counseling." Moreover, Hoffmann adds that obesity is both a scientific and a political matter, and has been "conceived of as unwanted eating behavior, lack of exercise, and lack of self-care." The author further writes - many obese persons feel that they are not respected and are socially isolated, and they meet with various forms of prejudice due to their weight and appearance. An alarmingly rising number of weight discrimination has been reported in the United States and elsewhere and has been reported in employment settings, in healthcare facilities and educational institutions per Hoffman. Negative stereotyping also exists that overweight people are lazy and noncompliant. ${ }^{(62)}$ The perception that overweight/oversized people are not able to function and perform like regular weight and regular sized people leads to discrimination and is framed by society, not necessarily shared by the overweight/oversized person. ${ }^{(63)}$

In a normative view, problems with the body are defined as a disease because they are considered undesirable. ${ }^{(64)}$ In a society where the bodily ideal is slender and fit - images of fat, badly-shaped bodies fall out of the norm. ${ }^{(65)} \mathrm{A}$ fat body signals to the observer that its owner is not able to control desire. For centuries, religious protestant teachings have lectured Western societies about the need to be humble and to control desire. Desire, in many ways, was interchanged with sin, and the body itself was conceptualized as a site of temptation. Fat and fatness, in other words, signal immorality and are incompatible with a protestant ethic that continues to inform many of Western societies' norms and values. Such a disparity with Western religious ethics has given rise to current social stigmatizations of overweight people as lazy, sloppy, dirty and worse. ${ }^{(66)}$ Given this conceptualization of obesity as a disease, obesity and being overweight, is a state that people including children cannot expect to want to be in and cannot possibly enjoy, and are expected to engage in treatment strategies, either in the form of dieting, increased exercise or more serious forms of medical intervention such as bariatric surgery. ${ }^{(67)}$

In the United States, research suggests that overweight and obese people experience being stigmatized ("fat Stigma") and discriminated against because of weight. Obesity negatively impacts almost every area of everyday life. ${ }^{(68)}$ By early childhood, weight-related teasing and bullying are common. As people move into adulthood, high body weight becomes a strong negative predictor of worse academic, career opportunity, and success. Obesity is also associated with worse treatment in health-care settings. Another great concern is that obesity is increasingly associated with poverty and income inequality in the United States and elsewhere-and intersects with other such risks for socioeconomic exclusion as minority ethnicity and female gender. This suggests that fat stigma may become a powerful force for structural violence, and hence an underlying factor in the creation of economic and health disparities. Fat stigma amplifies exposures to psychosocial stress by forcing people into downwardly mobile economic

\footnotetext{
59 Jon D. Wisman and Kevin W. Capehart. "Creative Destruction, Economic Insecurity, Stress, and Epidemic Obesity”, 966

60 Jon D. Wisman and Kevin W. Capehart. "Creative Destruction, Economic Insecurity, Stress, and Epidemic Obesity", 941

${ }^{61}$ Bjørn Hofmann, “Obesity as a Socially Defined Disease: Philosophical Considerations and Implications for Policy and Care". Health Care Anal, 24 (2016): 91

62 Bjørn Hofmann, "Obesity as a Socially Defined Disease: Philosophical Considerations and Implications for Policy and Care”, 92

63 Bjørn Hofmann, "Obesity as a Socially Defined Disease: Philosophical Considerations and Implications for Policy and Care", 93

${ }^{64}$ Vries, Jantina de. "The obesity epidemic: medical and ethical considerations", 59

${ }^{65}$ Vries, Jantina de. "The obesity epidemic: medical and ethical considerations", 60

${ }^{66}$ Vries, Jantina de. "The obesity epidemic: medical and ethical considerations", 61

${ }^{67}$ Vries, Jantina de. "The obesity epidemic: medical and ethical considerations", 62

${ }^{68}$ Alexandra A. Brewis \& Amber Wutich, "A World of Suffering? Biocultural Approaches to Fat Stigma in the Global Contexts of the Obesity Epidemic." Annals of the Anthropological Practice 38.2 (2015):269.
} 
pathways; the stigma may make them more likely to live in obesogenic environments with restricted opportunities for exercising and eating healthy foods. ${ }^{(69)}$

S. Jay Olshansky and colleagues point out to the critical role of interrelated structural factors such as poverty, food systems, work patterns, and the built environment that depicts a portrait of the reasons behind people gaining excess weight and the difficulty of losing this excess weight gain. The apparent association between obesity, social class, and ethnicity lead to the observation of a strong racial- and class component to weight distribution in modern societies. Prevalence of overweight and obesity is significantly higher in the poorer 'classes' and the ethnic minorities than in the richer classes and in the native population in almost all Western societies. Numerous reasons including parental education and behavior, are normally mentioned to account for such differences; but the prevalence of obesity appears to follow class structures and segregation in societies that have since long embraced the principle of equality. This triggers profound social reflection not only on the income distribution in society but also on the moral injustice of an unequal distribution of health and education across society. ${ }^{(70)}$

\section{ENVIRONMENTAL CHANGES, POLICY CREATION AND GOVERNMENT INTERVENTION}

There is a correlation between obesity and negative effect on the longevity of an estimated 5 to 20 years of people's lives being reduced due to obesity. This negative effect of obesity can be critical on the future life expectancy of the youth population and in public policy decision-making. ${ }^{(71)}$ To ensure that life expectancy in the modern era is not reduced, there is a need for populationlevel interventions that will effectively reduce obesity. It has also been pointed out by Boyd Swinburn and colleagues that the health and life expectancy of minorities may be affected the most by obesity, because of limited access to healthcare, and due to increased childhood and adult obesity within these subgroups. ${ }^{(72)}$ Ronald L. Sandler states that in order to achieve WHO's target to interrupt this rise in obesity there is a need to create healthier food environments. Although there exist substantial debate and questions around who is responsible for the delivery of effective actions and what those actions might be, these debates are usually derailed towards the individual and collective responsibilities, and as the author points out, towards hard regulatory or fiscal interventions, and soft voluntary, education-based approaches. ${ }^{(73)}$ However, it has been argued that strengthening of accountability of systems across all actors will be required to reduce obesity. This section looks at the recommended environmental changes, policy creation, and interventions.

\section{A. Responsibility, income inequality, and consumption}

Obesity raises ethical dilemmas such as "whose responsibility is it to address obesity?" (74) Where there is access to healthy food and physical exercise, obesity is a matter of personal responsibility. However, people's food choices are structured by cost, taste, availability, social norms and convenience. Poverty and income inequality are significant factors, in many places that amount is not enough to afford a nutritionally adequate diet, and people have no control over their socioeconomic conditions. ${ }^{(75)}$ Poverty along with food aid will need to be addressed to eliminate food insecurity and create a sustainable dependency. There is a need for more comprehensive assistance in the right form. ${ }^{(76)}$ Moreover, children have opportunities to get unhealthy food outside their parent's

\footnotetext{
${ }^{69}$ Alexandra A. Brewis \& Amber Wutich, "A World of Suffering? Biocultural Approaches to Fat Stigma in the Global Contexts of the Obesity Epidemic", 270

${ }^{70}$ Vries, Jantina de. "The obesity epidemic: medical and ethical considerations", 64.

${ }^{71}$ S. Jay Olshansky, et al." A Potential Decline in Life Expectancy in the United States in the 21st Century". New England Journal of Medicine 352 no 11 (2005): 1140

72 S. Jay Olshansky, et al." A Potential Decline in Life Expectancy in the United States in the 21st Century", 1143

73 Boyd Swinburn et al. "Obesity 6: Strengthening of accountability systems to create healthy food environments and reduce global obesity." Lancet, 385 (2015): 2534

${ }^{74}$ Ronald L. Sandler, Food ethics: The basics, 157

75 Ronald L. Sandler, Food ethics: The basics, 48

${ }^{76}$ Ronald L. Sandler, Food ethics: The basics, 63
} 


\section{THE JOURNAL OF HEALTHCARE ETHICS \& ADMINISTRATION}

Vol. 5 | No. 1 (Fall/Winter 2019)

supervision; examples include vending machines and school luncheons. While it is undoubtedly true that parents are responsible for health and well-being of their children, it does not follow that parents are solely responsible. (77)

Corporations that sell unhealthy foods are not only merely satisfying people's preferences; they are shaping their preferences with only the intent of making profits, aided in their goals by maintaining and growing public consumption of unhealthy foods. They can achieve their profit-making goals through promoting public demand by lobbying for commerce, labor and agricultural policies that keep the cost of processed food low in comparison to healthier foods. Another way is by making them widely and easily available through franchise proliferation and globalization and vending machines; and by advertising. Fast food companies spent USD 4.6 billion on advertising in 2012, and the food and beverage industry as a whole spent well over USD 10 billion, whereas, only $\$ 116$ million was spent on fruits and vegetables that same year. A great deal of this advertising was aimed at children. On children's programming, 95\% were for foods high in fat, sugar, and sodium. Cartoons and other characters are used to appeal to the children, often highlighting toys and games that come with the food, resulting in children asking their parents for these products and increasing their consumptions. ${ }^{(78)}$

Advertising of unhealthy food targeting children is considered unethical since they are manipulating children into harming to their selves to make a profit. Eating unhealthy, fatty foods are bad for children's health immediately as well as long term overweight, and obesity increases the risk for both childhood, and adult diseases, including diabetes, heart disease, asthma and depression. As the poverty, utilization and distribution factors indicate, food insecurity is not always or even, usually due to limitations in food production or food availability. It is about people having the physical, social and economic resources or capabilities to secure food for themselves and their families. Social, political and economic institutions and policies are enormously influential on people's capabilities concerning food security, particularly important since they affect pretty much everything, such as empowering some actors over others, change incentive structures, and set mandates and so on. ${ }^{\text {(79) }}$

Bjørn Hofmann also points out that despite signs of stabilization in some populations, the effects of the consistently high prevalence of obesity on population health are far-reaching. He argues that societies are burdened by premature mortality, morbidity associated with many chronic disorders, and negative effects on health-related quality of life, and the challenge to inform public policies and health services about the effect of these health burdens are indeed pressing. ${ }^{(80)}$ Obesity has garnered significant concerns amongst health policymakers and has raised attention in health care. According to Hoffman, obesity can conflict with aesthetic, moral, or other social norms; and biomedical solutions to social problems can result in medicalization and enhance stigmatization and discrimination of persons based on appearance or behavior. Such approaches to social problems with biomedical means, according to the Hoffman will not be permanent but act as quick fix medical solutions that will only serve the commercial and professionals' interest rather than serving the health and overall welfare of individuals; and may halt more sustainable structural solutions. ${ }^{(81)}$ It is important that health insurers, health care professionals, and health policymakers are cautious, and sensitive, making sure that all patients, including overweight and obese patients, are provided the care with respect and dignity. Therefore, according to Alexandra A. Brewis and Amber Wutich, socially defining obesity as a disease, may turn into a wise health policy, that will increase population health - by addressing the social determinants that cause obesity, such as access to high quality food and also the marketing system, disparities in socioeconomic status, transportation system, and consumption growth. ${ }^{(82)}$

As public health campaigns gear up to take on the growing challenge of obesity, basic knowledge about the sociocultural bases of fat stigma will be vital to their success. Such public health campaigns should be informed by an understanding of when and how fat stigma helps or hurts people-both in terms of economic and biocultural impacts. Additionally, it is essential for health providers to determine when fat stigma triggers or undermines the critical behavior change desired in clinical and public health interventions. Because fat stigma carries a clear and well-documented risk of harming those struggling with their weight, it should be used cautiously in clinical and public health settings. ${ }^{(83)}$ Public health has an important, but limited role in stopping the obesity epidemic. It is not the role to force people to eat healthier or compel people to exercise more, but to make it easier for people to

\footnotetext{
${ }^{77}$ Ronald L. Sandler, Food ethics: The basics, 159

78 Ronald L. Sandler, Food ethics: The basics, 158

79 Ronald L. Sandler, Food ethics: The basics, 50

${ }^{80}$ Y Claire Wang, et al. "Obesity 2: Health and economic burden of the projected obesity trends in the USA and the UK", 816

81 Bjørn Hofmann, "Obesity as a Socially Defined Disease: Philosophical Considerations and Implications for Policy and Care", 86

82 Bjørn Hofmann, "Obesity as a Socially Defined Disease: Philosophical Considerations and Implications for Policy and Care", 96

${ }^{83}$ Alexandra A. Brewis \& Amber Wutich, "A World of Suffering? Biocultural Approaches to Fat Stigma in the Global Contexts of the Obesity Epidemic", 279
} 


\section{THE JOURNAL OF HEALTHCARE ETHICS \& ADMINISTRATION}

Vol. 5 | No. 1 (Fall/Winter 2019)

obtain healthy diet and be physically active by minimizing factors that undermine and overwhelm them. There is a big difference between regulating people's behavior directly and regulating the environment in which they live. ${ }^{(84)}$

With the rise of obesity and non-communicable diseases (NCD) worldwide, governments have been recommended by the WHO to engage all societal sectors to reduce NCD successfully. Diverse stakeholders can share the responsibility to implement, monitor and evaluate policies without compromising the integrity of these efforts. ${ }^{(85)}$ Governments are discouraged from sharing or relinquishing their responsibility for policy development with non-governmental stakeholders, especially unhealthy commodity industries that manufacture and market fast foods, sweetened beverages, and alcohol. Governments are accountable to the people who elect them and are expected to protect the policy-making process from commercial interests by upholding robust standards to promote public interests over private interests, ensure transparency and manage conflicts of interest. There has been a lot of contention that minimal progress has been made in developing policies that support healthy food environments due to commercial interest-group pressures on government policy. Governments are responsible for developing a policy to support healthy food environments and ensure that all stakeholders follow recommended guidelines and laws. ${ }^{(86)}$

\section{B. Promotion of food, regulation, and public health}

An ethical issue that has become prominent in the context of obesity is the use of governmental power to promote public health. It is widely agreed that government has a vital role to play in addressing the obesity epidemic. ${ }^{\text {(87) }}$ Autonomy generally favors allowing people the right to choose and not be coerced. Given this presumption, the government has to have a good reason for their interest or stand to intervene. One commonly recognized justification is that the state can intervene when behavior poses risks to others, but this does not apply to food. Coercive food policies cannot be applicable. ${ }^{(88)}$ Questions that arise are related to the methods that should be employed - educational and informational or nudge people towards better choices with persuasion and programs; should they intervene in the market place by taxing or restricting advertisement towards children, should certain types of food be prohibited?

There is a need for directing visibility towards the increasing visibility of the obesity epidemic and the need for leading research toward effective environmental and policy solutions that address changes in diet and physical activity. ${ }^{(89)}$ Public policies that will improve infrastructure for improved physical activities such as sidewalks, bicycling paths are critical. Healthcare systems and providers will also need proper education and training to recognize the importance of not fat-shaming individuals, or to put aside their bias against overweight individuals. Better partnerships with schools and communities and other entities will also be required to address the social and environmental causes of childhood obesity. ${ }^{(90)}$ Prevention efforts and responsibility for the problem needs to be identified and acknowledged. It is our job - as adults, as parents, caregivers, schools, community, and the state - to provide and ensure a healthy life for our children. Children are vulnerable because of the limitations in their access to food and their limited ability to make healthy food choices, and they are easy targets by marketing agencies.

Obesogenic environments make it easy for children to get access to unhealthy, high-fat, low-nutrient and sugar-dense food choices - because of availability, low prices, and also creative marketing tactics. ${ }^{(91)}$ The commercial advertising and marketing of food and beverages are intersecting factors that influence the diets and diet-related health of children and youth. Many studies indicate that, among many factors, food and beverage marketing influences the preferences and purchase requests of children, influences short-term consumption, may contribute to less healthful diets, and contributes to an environment that puts their health at risk. Kersh R. and colleagues point out that food advertising affects the children's preferences, and influences purchase behaviors, and consumption habits. Food and beverage advertising on television influences children, ages to 2-11 years, to prefer and

\footnotetext{
${ }^{84}$ Deborah Cohen, A Big Fat Crisis: The Hidden Forces Behind the Obesity Epidemic - and How We Can End It, 117

${ }^{85}$ Vivica I Kraak et al. "An accountability framework to promote healthy food environments." Public Health Nutrition, 17 no.11 (2013): 2467

${ }^{86}$ Vivica I Kraak et al. "An accountability framework to promote healthy food environments." 2648

${ }^{87}$ Ronald L. Sandler, Food ethics: The basics, 160

${ }^{88}$ Ronald L. Sandler, Food ethics: The basics, 161

${ }^{89}$ William H. Dietz. "The Response of the US Centers for Disease Control and Prevention to the Obesity Epidemic," 577

${ }^{90}$ William H. Dietz. "The Response of the US Centers for Disease Control and Prevention to the Obesity Epidemic", 581

${ }^{91}$ Kersh R, Stroup DF, Taylor WC. "Childhood obesity: a framework for policy approaches and ethical considerations", 3
} 


\section{THE JOURNAL OF HEALTHCARE ETHICS \& ADMINISTRATION}

Vol. 5 | No. 1 (Fall/Winter 2019)

purchase high-calorie, and low-nutrient foods and beverages. ${ }^{(92)}$ Successful intervention and prevention measures must shift its focus from individual or family responsibility toward the environment. According to Deborah Cohen, public officials have a responsibility to intervene through policies that control the conditions of sale. This can be exercised in schools, by limiting what they offer in terms of unhealthy food to children. Advertisements of high-fat, low-nutrient foods that target young children can be restricted by requiring calorie labels. Moreover, healthier alternatives such as fruits and vegetables can be subsidized; and restricting certain ingredients such as trans-fat, and the number of food commercials that target children can be a positive step toward improving the environment. ${ }^{(93)}$

Neighborhood factors, such as safety and crime rates are associated with low-income neighborhoods, and must also be taken into consideration when implementing policies. If the area is not safe and has a high crime rate, then that can be an influence on the child's ability to spend time outside, and in various physical activities. Lower-income neighborhoods may also have fewer recreational activities and supermarkets with fresh and inexpensive produce, and often have more fast-food restaurants and fewer healthy and affordable options. Governments must take care to prevent their actions from affecting certain communities disproportionately. Although food industry officials deny that marketing has any effect on consumers, marketing is known to have a substantial impact on consumers. Currently, the burden is on the consumers to figure out their nutritional needs and resist temptation. However, targeting this epidemic at the local level, public health departments could establish benchmarks and standards that would require businesses to ensure that food they serve will not only increase people's risk for diseases, but also enhance the food awareness, ultimately favoring consumer health by increasing customer's awareness. ${ }^{(94)}$ The situation today in the modern food environment is the burden for avoiding unhealthy foods and assembling a healthy diet is entirely on the individual. For a healthy diet, we have to regulate both the quantity and quality of food. ${ }^{(95)}$

According to Shiriki K. Kumanyika, our societal obligation is to protect and nurture children. Therefore, it must be emphasized that children are not in any position to controlling and fending for themselves in an obesity-promoting environment. Underlying ethical principles that support the rights of the children to grow and develop in healthy environments should be given priority in policies to resolve the childhood obesity epidemic in ways that are socially acceptable and sustainable. Adding child rights-based approaches that enable the principle supporting legal actions that regulate the marketing of unhealthy beverages and foods to children can be an appropriate first step. The author further adds that this approach can elevate the rights of children that supersede the conflicting rights claimed by food marketers. Moreover, the author notes that ethical principles should be leveraged to justify interventions that represent children's rights, when applicable, as opposed to private corporations. Kumanyika emphasizes that "societal outcomes are determined by how these principles become priorities and are made operational through power dynamics; and these priorities, assigned to protecting the rights of different entities depend on societal attitudes." The author additionally argues that "decisions regarding who wins or loses must be justified and made palatable in the context of broader societal values and norms." (96)

As the prevalence of obesity grows, and with it the costs of dealing with its associated health problems, the need for society to take stronger action is becoming increasingly apparent. Regulating food accessibility is a promising way to control obesity. No single policy will be enough. Policies that address obesity need to be multipronged, incorporating a mix of approaches that include restrictions on access to problem foods, reduction of impulse marketing, point-of-purchase warnings, and portion controls. (97) Currently, there are not physical-activity-related entitlements or safety net support systems that children or adults can count on to help them get moving. It is up to individuals to figure out for themselves how to get enough exercise. Policies that incorporate opportunities for physical activities - transportation policies and urban design affect people's ability to walk to work, school and services; and educational policies relevant to whether school days include time for gym and recess are necessary for having an effective impact on obesity. ${ }^{(98)}$

\footnotetext{
92 "Overview if the IOM Report on Food Marketing To Children And Youth: Threat or Opportunity?" Institute of Medicine, Fact Sheet (2005): 4

93 Kersh R, Stroup DF, Taylor WC. "Childhood obesity: a framework for policy approaches and ethical considerations", 4

94 Deborah Cohen, A Big Fat Crisis: The Hidden Forces Behind the Obesity Epidemic - and How We Can End It, 118

95 Deborah Cohen, A Big Fat Crisis: The Hidden Forces Behind the Obesity Epidemic - and How We Can End It, 119

${ }^{96}$ Shiriki K. Kumanyika. "A Question of Competing Rights, Priorities, and Principles: A Postscript to the Robert Wood Johnson Foundation Symposium on the Ethics of Childhood Obesity Policy." Prev Chronic Dis 8: no. 5(2011):1

97 Deborah Cohen, A Big Fat Crisis: The Hidden Forces Behind the Obesity Epidemic - and How We Can End It,141

${ }^{98}$ Deborah Cohen, A Big Fat Crisis: The Hidden Forces Behind the Obesity Epidemic - and How We Can End It,164
} 


\section{THE JOURNAL OF HEALTHCARE ETHICS \& ADMINISTRATION}

Vol. 5 | No. 1 (Fall/Winter 2019)

\section{CONCLUSION}

Obesity is a result of increased intake of high caloric foods, and decreased energy expenditure. Increasing cues to eat- television commercials has increased with obesity, with a staggering $\$ 4.6$ billion spent by the fast food industry on advertising unhealthy products in 2012 alone, with many of those ads specifically targeting children and teens. ${ }^{(99)}$ Unhealthy food ads are also targeted more heavily toward minorities, an estimated more than 84 percent of all foods and beverages advertised to children on Spanishlanguage television shows were unhealthy according to a study by Robert Wood Johnson Foundation in 2013. (100,101) The food industry is simply taking advantage of our natural interest in food and our innate instincts to survive. ${ }^{(102)}$ There is a much-trumpeted relationship between obesity and "food deserts." (103) According to Cohen, the problem is less about access to healthy food than it is about being inundated with too much unhealthy food. ${ }^{(104)}$ As Deborah Cohen rightly states, we live in a 'food swamp,' where we have access to food $24 / 7$, most of it is unhealthy. ${ }^{(105)}$ Today we need government intervention in stopping obesity epidemics as it did in the nineteenth century with stopping the infectious diseases - using public health principles that addressed environmental risks rather than individual behaviors. ${ }^{(106)}$ We need public policies that can address the obesity crisis by improving access to healthy food, and reducing poverty. ${ }^{(107)}$ Policies need to focus on obesity by creating a more stable environment in which individuals can automatically make healthy decisions about eating and exercising. ${ }^{(108)}$ Transportation policies and urban design can affect people's access to physical activity. Creating safer neighborhoods can provide safe public spaces for sports. Implementing policies with all of these factors can be instrumental in eliminating obesity.

\section{BIBLIOGRAPHY}

Apovian, Caroline M. "The Obesity Epidemic - Understanding the Disease and the Treatment". The New England Journal of Medicine, 374 no 2 (2016): 177-179

Brewis, Alexandra A. \& Wutich, Amber "A World Of Suffering? Biocultural Approaches To Fat Stigma in the Global Contexts of Obesity Epidemic" Annals of Anthropological Practice 38.2 (2015): 269-283.

Brewis, Alexandra. Obesity: Cultural and biocultural perspectives. New Brunswick, New Jersey and London: Rutgers University Press, 2011

Coleman-Jensen, Alisha, Matthew P. Rabbitt, Christian A. Gregory, and Anita Singh. "Household Food Security in the United States in 2017." USDA ERS, (2018). Available at: https://www.ers.usda.gov/publications/pubdetails/?pubid=90022.

Cohen, Deborah. "A Big Fat Crisis: The Hidden Forces behind the Obesity Epidemic - and How We Can End It." New York, NY: Nations Books, 2014

Dietz, William H. "The Response of the US Centers for Disease Control and Prevention to the Obesity Epidemic" Annual Review of Public Health 36 (2015): 575-596

Fardet, Anthony and Boirie, Yves. "Associations between food and beverage groups and major diet-related chronic diseases: an exhaustive review of pooled/ meta-analyses and systematic reviews" Nutrition Reviews, 72 $(12): 741-762$

\footnotetext{
99 "'Fast Food Facts': Q\&A with the Yale Rudd Center for Food Policy \& Obesity." RWJF, (2013).

100 Deborah Cohen, A Big Fat Crisis: The Hidden Forces Behind the Obesity Epidemic - and How We Can End It, 77

101 "Unhealthy Food Ads Dominate Spanish TV Shows for Kids." RWJF, (2013).

102 Deborah Cohen, A Big Fat Crisis: The Hidden Forces Behind the Obesity Epidemic - and How We Can End It, 78.

103 Deborah Cohen, A Big Fat Crisis: The Hidden Forces Behind the Obesity Epidemic - and How We Can End It, 79.

104 Deborah Cohen, A Big Fat Crisis: The Hidden Forces Behind the Obesity Epidemic - and How We Can End It, 80

105 Deborah Cohen, A Big Fat Crisis: The Hidden Forces Behind the Obesity Epidemic - and How We Can End It, 94

${ }^{106}$ Deborah Cohen, A Big Fat Crisis: The Hidden Forces Behind the Obesity Epidemic - and How We Can End It, 109

107 Ronald L. Sandler, Food ethics: The basics, 162

${ }^{108}$ Deborah Cohen, A Big Fat Crisis: The Hidden Forces Behind the Obesity Epidemic - and How We Can End It, 111
} 


\section{THE JOURNAL OF HEALTHCARE ETHICS \& ADMINISTRATION}

Vol. 5 | No. 1 (Fall/Winter 2019)

Fortuna, Jeffrey L. "The Obesity Epidemic and Food Addiction: Clinical Similarities to Drug Dependence". Journal of Psychoactive Drugs, 44 no 1(2012): 56-63

Hammond, Robert, Rodoniki Athanasiadou, Silvia Curado, Yindalon Aphinyanaphongs, Courtney Abrams, Mary Jo Messito, Rachel Gross, Michelle Katzow, Melanie Jay, Narges Razavian, and Brian Elbel. "Predicting Childhood Obesity Using Electronic Health Records and Publicly Available Data." Plos One 14, no. 4 (2019): 1-18.

Hofmann, Bjørn. "Obesity as a Socially Defined Disease: Philosophical Considerations and Implications for Policy and Care". Health Care Anal (2016) 24:86-100

Nestle, Marion. "Food Marketing and Childhood Obesity - A Matter of Policy". The New England Journal of Medicine, 354 no 24 (2006): 2527-2529

Kraak, Vivica I. et al. "An accountability framework to promote healthy food environments" Public Health Nutrition, 17 no.11 (2013): 2467-2483

Kersh, R., Stroup, DF., and Taylor, WC. "Childhood obesity: a framework for policy approaches and ethical considerations." Prev Chronic Dis 2011:8(5): 1-5

Kumanyika, Shiriki K. "A Question of Competing Rights, Priorities, and Principles: A Postscript to the Robert Wood Johnson Foundation Symposium on the Ethics of Childhood Obesity Policy." Prev Chronic Dis 8: no. 5(2011): 1-4

Lawrence, Shawn., Hazlett, Rehekah and Hightower, Peggy. "Understanding and Acting on the Growing Childhood and Adolescent Weight Crisis: A Role for Social Work." National Association of Social Workers, (2010): 147-153

"Overview of the IOM Report on Food Marketing To Children and Youth: Threat or Opportunity?" Institute of Medicine, Fact Sheet (2005): 1-4

Puhl, Rebecca M. and Heuer, Chelsea A. "Obesity Stigma: Important Considerations for Public Health." American Journal of Public Health, 100, no 6 (2010): 1019-1028

Robert Wood Johnson Foundation (RWJF). (2019). "Unhealthy Food Ads Dominate Spanish TV Shows for Kids." [online] Available at: https://www.rwjf.org/en/library/articles-and-news/2013/05/unhealthy-food-adsdominate-spanish-tv-shows-for-kids.html

Robert Wood Johnson Foundation (RWJF). (2013): "'Fast Food Facts': Q\&A with the Yale Rudd Center for Food Policy \& Obesity." RWJF. Retrieved from: https://www.rwjf.org/en/blog/2013/11/_fast_food_factsq.html.

Ryan T. Hurt et al. "The Obesity Epidemic: Challenges, Health Initiatives, and Implications for Gastroenterologists" Gastroenterol Hepatol, 6 no 12(2010): 780-792

Sandler, Ronald L. Food ethics: The Basic. Abingdon: Routledge, 2015

S. Jay Olshansky, et al." A Potential Decline in Life Expectancy in the United States in the 21st Century". New England Journal of Medicine, 352 no 11 (2005): 1138-1145

Swinburn, Boyd et al. "Obesity 6: Strengthening of accountability systems to create healthy food environments and reduce global obesity." Lancet 2015; 385: 2534-45

Ten Have, Marieke "Ethical aspects of obesity prevention". Best Practice \& Research Clinical Gastroenterology 28 (2014): 303-314

Ten Have, Marieke et al. "An overview of ethical frameworks in public health: can they be supportive in the evaluation of programs to prevent overweight?" BMC Public Health 2010, 10:1-11

Tengland, Per-Anders. "Behavior Change or Empowerment: On the Ethics of Health-Promotion Strategies". Public Health Ethics, 5(2012): 140-153.

Upshur, Ross. "What Does Public Health Ethics Tell (Or Not Tell) Us About Intervening in Non-Communicable Diseases? Bioethical Inquiry, (2013) 10:19-28

Vries, Jantina de. "The obesity epidemic: medical and ethical considerations". Sci Eng Ethics 13(2007):55-67

Wang, Y. Claire et al. "Severe Obesity in Adults Cost State Medicaid Programs Nearly \$8 Billion In 2013" Health Affairs, 34, no.11 (2015):1923-1931

Wang, Y. Claire et al. "Obesity 2: Health and economic burden of the projected obesity trends in the USA and the UK." Lancet 2011; 378: 815-25

Wisman, Jon D. and CAPEHART, Kevin W. "Creative Destruction, Economic Insecurity, Stress, and Epidemic Obesity". American Journal of Economics and Sociology, 69 no. 3 (2010): 936-982 


\section{THE JOURNAL OF HEALTHCARE ETHICS \& ADMINISTRATION}

Vol. 5 | No. 1 (Fall/Winter 2019)

World Health Organization (WHO). (2016). "Report to the Commission On: ENDING CHILDHOOD OBESITY." Retrieved from http://apps.who.int/iris/bitstream/10665/204176/1/9789241510066_eng.pdf?ua=1

World Health Organization (WHO). "WHO: Fact Sheet." (2016)

Retrieved from: http://www.who.int/mediacentre/factsheets/fs311/en/

World Health Organization (WHO). "Fact sheets: overweight and obesity: key facts."

Retrieved from: http:// www.who.int/news-room/fact-sheets/detail/obesity-and-overweight. 